ISSN 2179-6750

\title{
Residência Multiprofissional em Saúde da Família: afirmação de um compromisso ético-político com o SUS
}

Multiprofessional Residence in Family Health: affirmation of an ethical-political commintment with SUS

Residencia Multiprofesional en Salud de la Familia: la afirmación de un compromiso ético y político para el SUS

Georgia Silva Romcy ${ }^{1}$; Cleide Lavieri Martins ${ }^{2}$

\section{Resumo}

As novas configurações da formação em saúde no Brasil são produzidas a partir da necessidade de constituição de processos formativos que se contraponham ao modelo biomédico centrado e de ensino fragmentado e de conteúdos. Nessa perspectiva, dialogamos sobre a Residência Multiprofissional em Saúde da Família e sua afirmação de um compromisso ético-político com o SUS, reconhecendo suas potencialidades e desafios.

Descritores: Atenção Básica; Formação em Saúde; Residência Multiprofissional em Saúde.

\begin{abstract}
The new configurations of health education in Brazil are produced based on the need to form training processes that are opposed to the focused biomedical model and fragmented teaching and content. From this perspective, we talk about the Multiprofessional Residency in Family Health and its affirmation of an ethical-political commitment with SUS, recognizing its potentialities and challenges.

Key-words: Primary Care; Health Formation; Multiprofessional Residence in Family Health.
\end{abstract}

\section{Resumen}

La nueva configuración de educación para la salud en Brasil se producen a partir de la necesidad de establecer procesos de formación que se oponen al modelo biomédico centrado y la educación fragmentada y de contenidos. Desde esta perspectiva, discutimos el Multidisciplinar Residencia en Salud de la Familia y su afirmación de un compromiso ético y político para el SUS, reconociendo su potencial y desafíos.

Palabras-claves: Atención Primaria; Formación para la Salud; Residencia Multiprofesional en Salud de la Familia.

Na conformação do nosso sistema de saúde, “existem vários SUS e vários setores privados

\footnotetext{
${ }^{1}$ Especialista pela Residência Multiprofissional em Saúde Mental pela Escola de Saúde Pública do Ceará. Mestranda do Programa de Pós-Graduação em Saúde Pública da Faculdade de Saúde Pública da Universidade de São Paulo. Av. Dr. Arnaldo, no 715, Cerqueira César, São Paulo, SP. CEP: 01246904. E-mail: georgiaromcy@usp.br

${ }^{2}$ Doutora em Saúde Pública pela Universidade de São Paulo. Professora Doutora do Departamento de Política, Gestão e Saúde da Faculdade de Saúde Pública da Universidade de São Paulo. Av. Dr. Arnaldo, n715, Cerqueira César, São Paulo, SP. CEP: 01246904. E-mail: cleide@usp.br
} 
ISSN 2179-6750

que estão imbricados em sua configuração" "1, sendo intensas as disputas no campo da saúde, e em específico na formação, para a produção de uma transformação nas práticas, relações e subjetividades, que se contraponha modelo biomédico centrado e de ensino fragmentado e de conteúdos.

Compreendendo também que as formações dos profissionais de saúde são produzidas em um tempo histórico e seu contexto, com nuances, disputas e diferentes projetos, ratificamos a afirmação de Ceccim e Feuerwerker de que o processo formativo "como política do SUS poderia se inscrever como uma 'micropotência' inovadora do pensar a formação, agenciamento de possibilidades de mudança no trabalho e na educação dos profissionais de saúde e invenção de modos no cotidiano da produção dos atos de saúde" ${ }^{2}$.

Dessa forma, nesse contexto de necessidade de mudanças nos processos formativos em saúde e com a premissa de que compete ao SUS o ordenamento da formação de seus trabalhadores, o Ministério da Saúde intensifica o fomento de ações nessa perspectiva, principalmente a partir da criação da Secretaria de Gestão do Trabalho e Educação em Saúde (SGTES), em 2003, e, consequentemente, com a formulação da Política Nacional de Educação Permanente em Saúde (PNEPS), em $2004^{3,4,5}$.

Das ações propostas pelo Ministério da Saúde está a Residência Multiprofissional em Saúde (RMS), modalidade de pós-graduação lato sensu, com duração de 2 anos, de dedicação exclusiva e destinada às categorias profissionais de saúde regimentadas na Resolução n²87/98 do Conselho Nacional de Saúde (CNS), com exceção da medicina ${ }^{6}$. Apesar de sua regulamentação ocorrer em 2005, a RMS, enquanto modalidade de ensino em serviço, tem experiências produzidas anteriores a esse período, não só tendo como campo de pratica as instituições hospitalares, mas também serviços de base comunitária ${ }^{7}$.

Rosa e Lopes afirmam que esse processo formativo foi idealizado sob a lógica de ser uma estratégia "de reorientação da Atenção Básica $(\mathrm{AB})$ para a implantação/reorganização dos serviços públicos embasados na lógica do SUS, com o objetivo de produzir as condições necessárias para a mudança no modelo médico-assistencial restritivo, ainda hegemônico, de atenção em saúde" 7 .

Esta perspectiva é consonante a principal estratégia de reformulação da $\mathrm{AB}$, a Estratégia de Saúde da Família (ESF), proposta de modelo assistencial "centrado na atenção primária e na promoção da saúde familiar, assim como na mudança da ênfase individual para a coletiva e familiar e da ação curativa e reabilitadora para a promotora da saúde ${ }^{3}$. Portanto, reordenar o modelo de atenção à saúde é também reformulação na formação dos profissionais que fazem e farão parte dele.

Assim, a ênfase de Saúde da Família na Residência Multiprofissional (RMSF), 
ISSN 2179-6750

principalmente no início de difusão desse processo formativo, e enquanto estratégia de transformação das práticas, foi fomentada de forma intensa, como apresenta o Ministério da Saúde na coletânea Residência multiprofissional em saúde: experiências, avanços e desafios, que expõe e discute diversas experiências de implementação e funcionamento dessa modalidade de ensino em serviço 5 .

Nos últimos tempos, têm sido publicadas produções científicas que expõem realidades e potencialidades dessa modalidade de formação, tanto para os profissionais quanto para os serviços de saúde, seja a partir da atuação dos diversos núcleos profissionais que a compõem ${ }^{8,9,10,11,12}$, seja a partir das implicações desse processo formativo nos serviços que fazem parte dos cenários de prática, em particular, na Atenção Básica ${ }^{3,4,13}$.

Essas experiências apresentam não só o aprimoramento específico de cada residente em seu fazer profissional, mas demonstram como as Residências Multiprofissionais em Saúde da Família, em seus mais diversos modos de se configurar, podem ser um espaço de construção da multiprofissionalidade e de encontro e formação dos trabalhadores dos serviços, um dispositivo de ampliação de acesso e de produção da integralidade no cuidado e até mesmo de inserção de núcleos profissionais que ainda não se faziam presente nas equipes dos serviços.

Reconhecer os desafios cotidianos para a implementação de uma Atenção Básica que consiga se efetivar seguindo os princípios do SUS, reconhecendo as necessidades de cada serviço e, consequentemente, das pessoas que se fazem presente neles (usuários, trabalhadores e gestores) e também a diversidade de programas de RMSF no país e suas dificuldades de produzirem a efetiva transformação das práticas, significa também considerar que mesmo com as adversidades, há potência nessa experiência quando elas estão efetivamente implicadas em cada pessoa que se faz presente nesses processos.

Em tempos que o SUS cotidianamente é atacado pelas mais diferentes frentes, não só no que concerne as suas ações e serviços, mas também seus princípios e projeto societário, reconhecer experiências e publicizá-las torna-se não só um desafio, mas também um compromisso éticopolítico e de resistência em defesa da vida.

\section{Referências}

1. Feuerwerker LCM. Micropolítica e Saúde: produção do cuidado, gestão e formação. $1^{\mathrm{a}}$ ed. Porto Alegre: Editora Rede Unida. 2012.

2. Ceccim RB, Feuerwerker LCM. O Quadrilátero da Formação para a Área da Saúde: ensino, gestão, atenção e controle social. Physis. 2004; 14(1):41-65. 
ISSN 2179-6750

3. Nascimento DDG, Oliveira MAC. Competências Profissionais e o Processo de Formação na Residência Multiprofissional em Saúde da Família. Saúde Soc. 2010; 19(4):814-827.

4. Domingos CM, Nunes EFPA, Carvalho BG. Potencialidades da Residência Multiprofissional em Saúde da Família: o olhar do trabalhador de saúde. Interface. 2015; 19(55):1121-1132.

5. Ministério da Saúde. Secretaria de Gestão do Trabalho e da Educação na Saúde. Departamento de Gestão da Educação na Saúde. Residência multiprofissional em saúde: experiências, avanços e desafios. Brasília: Ministério da Saúde; 2006.

6. Lei $\mathrm{n}^{\circ} 11.129$ de 30 de junho de 2005. Institui o Programa Nacional de Inclusão de Jovens ProJovem; cria o Conselho Nacional da Juventude - CNJ e a Secretaria Nacional de Juventude; altera as Leis $\mathrm{n}^{\mathrm{o}} \mathrm{s} 10.683$, de 28 de maio de 2003, e 10.429, de 24 de abril de 2002; e dá outras providências. Brasília: Ministério da Saúde; 2005.

7. Rosa SD, Lopes RE. Residência Multiprofissional em Saúde e Pós-Graduação Lato Sensus no Brasil: apontamentos históricos. Trab Educ Saúde. 2010; 7(3):479-498.

8. Langoni CS, Valmorbida LA, Resende TL. A introdução de atendimentos por fisioterapeutas em unidades da atenção primária em saúde. Rev Bras Promoç Saúde. 2012; 25(3):261-270.

9. Paiva LFA, Souza, FR, Savioli KC, Vieira, JL. A terapia ocupacional na residência multiprofissional em saúde da família e comunidade. Cad Ter Ocup UFSCar. 2013; 21(3):595-600.

10. Cezar PK, Rodrigues PM, Arpini DM. A psicologia na estratégia de saúde da família: vivências da residência multiprofissional. Psicol: ciênc e prof. 2015; 35(1):211-224.

11. Santos IG, Batista NA, Devincenzi MU. Residência multiprofissional em saúde da família: concepção de profissionais de saúde sobre a atuação do nutricionista. Interface. 2015; 19(53):349-360.

12. Zanin LE, Albuquerque IMN, Melo DH. Fonoaudiologia e estratégia de saúde da família: implicação da dimensão estrutural na qualidade da atenção à saúde fonoaudiológica. Audiol Commun Res. 2015; 20(3):255-261.

13. Silva MMS, Dias MAS, Saraiva MJG, Silva MRF, Vasconcelos MIO. A Produção de Tecnologias Enquanto Efetividade da Residência Multiprofissional em Saúde da Família. In: Dias MSA, Silva MMS, Souza FL, Gadelha AKS, Alves EAS, organizadores. Tecnologias Leves em Saúde: saberes e práticas da residência multiprofissional na estratégia saúde da família. $1^{\text {a }}$ ed. Porto Alegre: Editora Rede Unida. 2015. p.13-37.

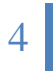

